\title{
Avaliação o Valor Gerado pelo Cliente: uma Revisão Bibliográfica
}

\author{
Aline Araújo Perini \\ Faculdade de Economia, Administração e Contabilidade (FEA) da Universidade de São Paulo \\ (USP) de Ribeirão Preto, Brasil \\ alineperini@iv.srv.br \\ Marcio Mattos Borges Oliveira \\ Faculdade de Economia, Administração e Contabilidade (FEA) da Universidade de São Paulo \\ (USP) de Ribeirão Preto, Brasil \\ lat2708@gmail.com

\section{Alberto Borges Matias} \\ Faculdade de Economia, Administração e Contabilidade (FEA) da Universidade de São Paulo \\ (USP) de Ribeirão Preto, Brasil \\ matias@usp.br

\section{Luciano Augusto Toledo} \\ Universidade Presbiteriana Mackenzie, São Paulo, Brasil \\ lat2708@gmail.com
}

\section{RESUMO}

O objetivo desse trabalho foi explorar os fatores que impactam e determinam o valor do cliente para a empresa e/ou acionistas. Com base em fundamentação teórica, foram evidenciadas as principais pesquisas, destacando as contribuições empíricas de cada caso e a contemplação dos vetores de valor para a empresa e/ou acionistas. Resultados sugerem que o advento da tecnologia da informação nas empresas tem proporcionado a produção de conhecimento para a tomada de decisão mais estruturada em relação à gestão de clientes por valor. Foram evidenciadas (9) nove pesquisas sobre análise de padrão de lucratividade, (8) oito sobre otimização de alocação de recursos, (5) cinco sobre aquisição, retenção e efeitos sociais e (4) quatro sobre avaliação de empresas por meio de clientes.

PALAVRAS-CHAVE: Avaliação de clientes. Valor vitalício do cliente. Lucratividade de cliente. Gestão de clientes 


\title{
Customer Value Generation: a Literature Review
}

\begin{abstract}
The objective of this work was to explore the factors that impact and determine the customer's value for the company and/or shareholders. Based on theoretical, it was evidenced the mainly researches, dealing with empirical contribution of each case and the value vectors contemplation for company and/or shareholders. Results suggest that the introducing information technology in the companies has been providing the knowledge production for decision models more structured for managing customers by value. Nine researches were evidenced on profitability pattern analysis, eight on optimize resources allocation, five on acquisition and retention and social effects and four about firm evaluation through customers.
\end{abstract}

KEY-WORDS: Customers' evaluation. Customer lifetime value. Customer value. Customer measuring. Modeling customer. 
É amplamente difundido que prospectar um novo cliente é mais custoso do que manter os clientes atuais em operação (GUPTA; LEHMANN, 2006; KOTLER, 2000; KUMAR; PETERSEN, 2005; RUST; ZEITHAML; LEMON, 2001). A busca pela vantagem competitiva sustentável pelas organizações é cada vez mais efêmera devido ao aumento do ambiente competitivo, no qual o cliente está cada vez mais informado e assediado pela concorrência. As empresas, nos últimos anos, têm se preparado para atender cada vez mais e melhor os clientes de um modo diferenciado, num nível superior da concorrência. Nesta perspectiva, as organizações têm investido volumosos recursos na implantação de sistemas de relacionamento e em campanhas de atração e retenção de clientes (JAIN; SINGH, 2002; RUST et al., 2004). Gupta e Lehmann (2006) afirmaram que o desempenho do marketing está atrelado à melhoria de métricas como conscientização, imagem da marca e nível de satisfação; e que muito raramente se considera as relações destas métricas com o valor da empresa, ou seja, é difícil apontar o retorno do volume de recursos gastos com estes programas para a empresa. Gupta e Lehmann (2006) enfatizaram que raramente um executivo de marketing sabe explicar quanto vale um ponto extra de satisfação no valor da empresa. As empresas se voltaram para as métricas de satisfação e qualidade, no entanto, há lacunas entre a relação de valor entregue ao cliente e o valor entregue para a empresa desfavorecendo a participação do marketing no hall das decisões estratégicas (LUKAS; WHITWELL; DOYLE, 2003; PETERSEN et al., 2009; RUST et al., 2004).

Se a imagem e a credibilidade do marketing estão desfavorecidas frente a outras funções da empresa, Rust et al. (2004), definiram então que a produtividade do marketing está atrelada ao processo de gerar valor ao acionista por meio da gestão de seus maiores ativos clientes e marcas. Srivastava, Shervani e Fahey (1998) foram os pioneiros na integração entre os conceitos de marketing e finanças, na mudança de concepção de gestão tradicional de finanças, antes voltada para ativos físicos e internos às empresas, agora voltadas à gestão de Ativos Baseados em Mercado, que evidencia as capacidades que uma empresa tem em alavancar vantagens através de fatores externos conquistados por relacionamento ou inteligência. 
A informação de mercado/cliente transformado em conhecimento organizacional é de importância preponderante para o alcance da vantagem competitiva (BARRETO, 2007; KUMAR; PETERSEN, 2005; XU; WALTON, 2005).

A empresa deve, deste modo, desenvolver o relacionamento com os clientes rentáveis, lutar pela conquista de novos clientes que se aproximam do comportamento de compra daqueles clientes que geraram lucro e deixar os clientes que geraram prejuízo migrarem para a concorrência (KOTLER, 2000).

A essência das informações, deste modo, não está inserida no perfil e na segmentação de mercado, mas sim, nas informações que refletem o comportamento de compra do consumidor, que é um processo dinâmico, provendo informações sobre clientes atuais, ex-clientes ou clientes inativos, novos clientes, clientes potenciais, clientes fiéis e clientes da concorrência. (BARRETO, 2007; XU; WALTON, 2005). Nesta perspectiva, os gerentes se deparam com inúmeros problemas para a tomada de decisão em relação a clientes, como, por exemplo, escolher em investir em propaganda ou em programas de lealdade ou melhorar a qualidade ou todos ou nenhum destes? Além das tomadas de decisões macros, há decisões sobre clientes, como a quem abordar, com que produto, em que momento, de que maneira? Que tipo de cliente prospectar e quais clientes reter? Quais clientes geram mais valor à empresa? Normalmente estas decisões são realizadas por julgamento entre os diretores e gerentes, porém estes executivos frequentemente têm pouca base para a tomada de decisão, salvo a intuição e a experiência (RUST; LEMON; ZEITHAML, 2004).

É evidente a influência dos clientes na eficiência operacional, financeira e estratégica dos negócios (LUKAS; WHITWELL; DOYLE, 2003; NENONEN; STORBACKA， 2008; SRINIVASAN; HANSSENS, 2009; STAHL; MATZLER; HINTERHUBER, 2002). Nenonen e Storbacka (2009) afirmaram que a performance das empresas corresponde às características das demandas, em primazia por clientes e que não há conhecimento e reconhecimento suficiente sobre as capacidades de gerenciar os relacionamentos dos clientes sob a dinâmica de mercado. Por outro lado, antecipar estas tendências posiciona a empresa de maneira ativa nas adversidades de mercado, market-driver ante market-driven (SRIVASTAVA; SHERVANI; FAHEY, 1998). 


\section{PROBLeMA DE PESQUISA}

Como avaliar economicamente clientes?

\section{OBJETIVO GERAL}

Apontar como os modelos de avaliação econômica de clientes na prática contemplam os vetores de valor aos acionistas.

\subsection{ESPECÍFICOS}

- Apontar os principais vetores do valor do cliente que impactam, determinam e influenciam a geração de valor para a empresa e/ou acionistas;

- Apontar os vetores mais frequentes nos modelos aplicados de avaliação econômica de clientes;

- Relacionar os vetores de valor à avaliação econômica de clientes.

\section{PROCEDIMENTOS METODOLÓGICOS}

A pesquisa caracterizou-se como exploratória e qualitativa por meio da análise de conteúdo, uma vez que se buscou levantar texto técnico em revistas/journals para o desenvolvimento do tema. Bardin (2008, p. 40) define que a intenção da análise de conteúdo é "a inferência de conhecimentos relativos às condições de produção (ou eventualmente de recepção), inferência esta que recorre a indicadores (quantitativos ou não). Para Zikmund (2003), estudos exploratórios são investigações que fornecem as informações necessárias para o desenvolvimento de uma pesquisa. Richardson (1999, p.17) completa afirmando que estudos exploratórios "tentam descobrir relações entre fenômenos" que sejam capazes de trazer contribuições para construção do conhecimento científico. Para Cooper e Shindler (2003, p. 32), "os termos empíricos e crítico referem-se às exigências para que o pesquisador teste as crenças subjetivas contra a realidade objetiva e tenha os resultados abertos para testes adicionais". Embora Flick (2009) tenha pronunciado que a aplicação de regras sistemáticas para análise qualitativa de conteúdo mostrase difícil, houve uma preocupação com a sistematização para prover maior 
confiabilidade e, consequentemente, promover a qualidade da pesquisa. Foi elaborada a sistematização formalizando o protocolo de pesquisa.

A investigação abordou estritamente artigos técnicos, publicados em periódicos em bancos de dados específicos disponíveis na internet que dispunham de pesquisas em bases de engenharia, tecnologia, matemática e ciências sociais como administração. Para Flick (2009), o critério de busca e de seleção pode ser por extensão ou profundidade. Para esta pesquisa optouse pelo critério de extensão, Flick (2009, p. 126) explica que "o critério de extensão busca representar o campo em sua diversidade de modo que possibilite apresentar indícios sobre a distribuição das formas. "Segundo Bardin (2008), a escolha de documentos é determinada pela regra de exaustividade, homogeneidade, representatividade e pertinência. Foram varridos os seguintes bancos: Portal Periódico da Capes; Google Scholar; SSRN: Social Science Research Network; Science Direct; AMA: American Marketing Association; Willi.

Investigou-se as palavras-chave usadas para levantamento nessas bases de dados foram: customer valuation, customer measuriement, modeling customer, customer metrics, customer lifetime value, customer equity, customer asset e customer management by value. Também houve inclusões por meio de indicação contida nos artigos no decorrer das leituras, estas inclusões foram importantes para compreender alguns fundamentos desta linha de pesquisa. A seguir foram selecionados artigos publicados após o ano de 2000. Para a primeira etapa de revisão bibliográfica foram necessárias inclusões anteriores a data de 2000 para a compreensão complementar dos fatores envolvidos no tema. Tal fato deve-se principalmente aos estudos mais recentes se referirem a termos que já são de domínio dos autores de referência no assunto. Para efeito desta presente pesquisa foi necessário recorrer a estudos anteriores. Inicialmente a primeira etapa de pré-análise da pesquisa foi realizada pelo método de análise flutuante que consiste em analisar e conhecer o texto deixando-se invandir por impressões e orientações com o objetivo de tornar operacional e sistematizar as idéias iniciais, de maneira a conduzir a esquema preciso do desenvolvimento das operações sucessivas, num plano de análise (BARDIN, 2008). Em seguida foram selecionados artigos foram catalogados no banco de dados Endnote $\AA$ e categorizados por data, 
autor, revista, assunto, palavras-chaves, resumos e número de citações, quando disponível. Os artigos foram divididos em modelos teóricos e práticos. Os teóricos foram utilizados para a descrição dos conceitos na revisão bibliográfica e como os atributos interagem no CLV e CE para a primeira etapa dessa pesquisa. Os práticos, por sua vez, participaram tanto do fundamento teórico na primeira etapa como da análise documental na segunda etapa.

O instrumento de pesquisa foi inspirado a partir de quadros elaborados pelas pesquisas de Rust, Lemon e Zeithaml (2004), Bowman e Narayandas (2004), Nenonen e Storbacka (2008) e Petersen et al. (2009). Para Flick (2009), a formalização do procedimento dá origem a um esquema uniforme de categorias, facilitando a comparação dos diferentes casos através dos quais ele se aplica. Ainda Mayring et al. (2004) e Flick (2009) definem as unidades analíticas como "unidade contextual" que é o maior elemento no texto que pode ser enquadrado em uma categoria e essa classificação visa uma análise de frequência das diferentes categorias.

A seguir a montagem do instrumento de pesquisa e inclusão de variáveis

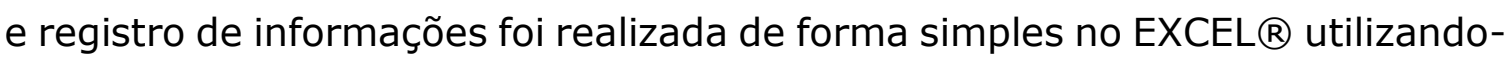
se a formatação de listas das células para facilitar a análise de frequência. Flick (2009) cita a generalização como parte integrante à categorização dos dados. Descreve ainda as etapas da indução analítica que têm por objetivo o foco em casos desviantes (que não se conseguiu categorizar) até que se crie uma relação universal fundamentada. Como já evidenciado, as derivações esperadas foram descritas e categorizadas na primeira etapa dessa pesquisa. Os passos para a indução analítica foram: formula-se uma definição preliminar do fenômeno a ser explicado; formula-se uma explicação hipotética do fenômeno; estuda-se à luz dessa hipótese para descobrir se ela corresponde aos fatos; se a hipótese não estiver correta, ou será reformulada, ou o fenômeno a ser explicado foi redefinido de forma que se excluísse esse caso; a certeza prática pode ser obtida após o estudo de um pequeno número de casos, mas a descoberta de cada caso negativo individual pelo pesquisador refuta a explicação e requer sua reformulação; estudam-se outros casos, redefine-se o fenômeno e reformulam-se as hipóteses até que se estabeleça uma relação universal; cada caso negativo requer uma definição ou uma reformulação. 


\section{REFERENCIAL TEÓRICO}

\subsection{APORTE TEÓRICO ACERCA DO VALOR E GESTÃO POR VALOR}

Kayo et al. (2006), atribuiram que o valor de mercado das empresas é dado pela combinação dos ativos tangíveis e intangíveis e afirmam que é complexo definir os limites do que é tangível do intangível, pois o próprio cálculo dos ativos tangíveis, principalmente imobilizados a valor de mercado, influencia no valor de mercado da empresa e, consequentemente, o valor dos ativos intangíveis.

De acordo com Goulart (2002), é de grande relevância o entendimento do conceito de ativos não só pelos acadêmicos como também para aqueles ligados diretamente às atividades práticas da contabilidade aplicada. No campo conceitual da contabilidade, a definição de ativos é um capítulo fundamental, pois sua definição e sua avaliação estão ligadas à multiplicidade de relacionamentos de receitas e despesas.

A classificação de ativos para Damodaran (1997) se distingue em três categorias: Ativos dos quais se tem a expectativa de geração de caixa futuro; Ativos que não geram caixa, mas possuem valor porque são escassos e/ou percebidos como valiosos; Ativos que não geram caixas, mas podem se tornar valiosos em caso de uma contingência.

Lev (2001), utilizando a visão de recursos, define ativo intangível como direito a benefícios futuros que não possui corpo físico nem financeiro e que interagem com os ativos tangíveis na criação de valor corporativo e no crescimento econômico. Para ele, o ativo intangível é gerado pela inovação, processos e práticas organizacionais e por recursos humanos. Para Goodchild e Callow (2001), os ativos intangíveis têm três grandes características, a saber: não escassez: caracteriza que os ativos intangíveis não são consumidos terminantemente no processo de produção, ao contrário dos ativos tangíveis; retornos crescentes: caracteriza que os ativos intangíveis podem ter vida útil indefinida, aumentando seu valor com o tempo, enquanto que os ativos tangíveis possuem vida útil determinada e são depreciados com o tempo até o valor residual; e efeito em rede: o valor da rede pode aumentar geometricamente, podendo se transformar em ativos estruturais quanto mais 
rápido tais informações forem disseminadas na rede. Também o uso de um intangível em um lugar ou tempo não impede seu uso em outro lugar.

O pronunciamento contábil da Comissão de Valores Mobiliários - CVM (2008, p. 6) define ativo intangível como "ativo não monetário identificável sem substância física". O mesmo pronunciamento especifica critérios para a identificação e reconhecimento contábil dos ativos intangíveis. Segundo este pronunciamento, o ativo intangível para ser identificado deve:ser separável, isto é, capaz de ser separado ou dividido da entidade e vendido, transferido, licenciado, alugado ou trocado, seja individualmente ou em conjunto com um contrato, ativo ou passivo relacionado; ou resultar de direitos contratuais ou de outros direitos legais, quer esses direitos sejam transferíveis quer sejam separáveis da entidade ou de outros direitos e obrigações.

No entanto, para registro contábil, a CVM $(2008$, p.8) regulamentou que o ativo intangível, além de identificado, deve ser reconhecido e somente será reconhecido quando: for provável que os benefícios econômicos futuros esperados atribuíveis ao ativo serão gerados em favor da entidade; e o custo do ativo possa ser mensurado com segurança.

A CVM (2008) deliberou que no caso de ativos que geram benefícios somente em conjunto com outros ativos deve ser considerado o conceito de unidades geradoras de caixa (UGC). A Comissão de Pronunciamento Contábil 01 - CPC 01 (2008) definiu unidades geradoras de caixa (UGC) como "menor grupo identificável de ativos que pode gerar fluxos de caixa a partir de seu uso contínuo e cujos fluxos são, de forma geral, independente dos fluxos de caixa de outros ativos ou grupos de ativos". Desta forma, embora a capacidade gestora de clientes identifique-os como ativos intangíveis, não são reconhecidos contabilmente pela dificuldade de se apontar os custos separadamente do desenvolvimento do negócio.

Segundo a tese de Kayo et al. (2006), ativos intangíveis podem ser sinônimos de capital intelectual, ativos do conhecimento, ativos invisíveis e goodwill. Para uma terminologia contábil é usado a nomenclatura goodwil, compreendida como prêmio, ágio ou fundo de comércio de acordo com a CVM (2008). Costa et al (2009), no seu trabalho, afirmou que todas estas denominações possuem o mesmo significado, embora trabalhos acadêmicos e práticos não atribuem o conceito contábil de goodwill corretamente. O goodwill 
contábil é definido pelo IASB (2004) e pelo FASB (2001) como "um ativo que representa os benefícios futuros advindos de outros ativos adquiridos em uma combinação de negócios que não são identificáveis individualmente e reconhecidos separadamente". Ainda o IASB (2004) é enfático ao definir o goodwill como uma premiação paga antecipadamente em reconhecimento ao benefício econômico futuro gerado pela sinergia de uma combinação de negócios ou sinergia gerada por ativos trabalhando conjuntamente. Costa et al. (2009, p. 2) define goodwill como "sendo a diferença entre o valor total da empresa e o patrimônio líquido avaliado a valores de mercado".

O goodwill, antes de tudo, é um ativo intangível, o intangível dos intangíveis, pois, segundo Costa et al. (2009), é um ativo intangível não identificado devido a sua natureza intrínseca e complexa na construção de valor aos acionistas. Existe uma diferença entre o goodwill existir efetivamente e ser registrado contabilmente no grupo de ativos. O tratamento contábil do goodwill é muito próximo da identificação e reconhecimento segundo os pronunciamentos da CVM (2008) de ativos intangíveis.

Para Costa et al. (2009), o goodwill pode existir a qualquer momento quando os ativos de uma entidade trabalharem em conjunto e produzirem retorno acima do que seria considerado normal. Na geração interna, porém, o goodwill não é contabilizado em virtude de sua não separabilidade da empresa, ele só tem valor se negociado juntamente com a empresa e só passa a ser reconhecido contabilmente após uma transação genuína, ou seja, adquirido externamente (CVM, 2008).

Kumar e Shah (2009), numa atitude empreendedora, testaram se a gestão de clientes por meio de estratégias de marketing influenciaria a capitalização de mercado, utilizando dados de uma indústria de tecnologia B2B e de uma de vestuário de varejo B2C. As estratégias de marketing adotadas para a empresa B2B foram melhorar a alocação de recursos, aquisição seletiva de clientes e análise do comportamento por canais de compra. Para a empresa B2C adotaram a seleção de clientes, vendas de produtos adicionais e comportamento por diferentes canais de compra.

Kumar e Shah (2009) afirmaram que a relação entre o valor da carteira de clientes e a capitalização de mercado é moderada pelos fatores de risco na forma de vulnerabilidade e volatilidade dos fluxos de caixa dos clientes. 
Concluíram empiricamente que é possível não só influenciar positivamente o preço da ação no mercado como também impulsionar as expectativas dos investidores. A empresa B2B apresentou um crescimento de 32,8\%, enquanto os três maiores competidores apresentaram 12,1\%. A empresa B2C apresentou um crescimento de $57,6 \%$ frente a $15,3 \%$ dos três maiores competidores.

Uma vez que a capacidade de geração de valor por meio da gestão de clientes está fora dos balanços das companhias (RUST et al., 2004; SRIVASTAVA; SHERVANI; FAHEY, 1998), estes são reconhecidos no goodwill, em que a melhor forma de expor estas informações deveria ser através dos relatórios gerencias e dos Relatórios da Administração (RA) (WIESEL; SKIERA; VILLANUEVA, 2007). No entanto, Colauto et al. (2008), concluíram que as companhias intangíveis intensivas brasileiras não evidenciam as informações sobre seus intangíveis nos Relatórios da Administração, salvo companhias que atuam no Novo Mercado quando se considerou um nível de significância baixo.

Os clientes são a corrente sanguínea de qualquer organização, sem eles a empresa não possui nem receitas nem lucros, pois são eles os responsáveis pela totalidade ou pela maior parcela dos fluxos de caixa que entregam o valor à companhia, aos acionistas e remuneram toda a cadeia de valor (GUPTA; LEHMANN, 2006). Empresas que relatam como estratégia do negócio criar valor ao cliente, aumentar fidelidade, satisfação e qualidade, acessar o valor do cliente e identificar as variáveis que mais impactam a geração de valor para os acionistas demonstram ser de vital importância tanto para uso gerencial quanto para os usuários externos sobre a performance, desenvolvimento da operação atual e futura da empresa (BAYÓN; GUTSCHE; BAUER, 2002; PEREZ; FAMÁ, 2006; KAYO et al., 2006; LEV, 2001; WIESEL; SKIERA; VILLANUEVA, 2007).

O campo de pesquisa de avaliação do CLV e CE estão inseridos na visão de ativos baseados em mercado (SRIVASTAVA; SHERVANI; FAHEY, 1998) e, portanto, as empresas estão expostas às temperanças, cabendo a elas serem reativas ou ativas frente aos fatores de mercado (RUST et al., 2004; SRINIVASAN; HANSSENS, 2009). Berger et al. (2006) propuseram uma estrutura conceitual de efeitos em cadeia para entender como o valor do cliente pode ser influenciado e afetar o valor para o SHV. Rust, Zeithaml e Lemon 
(2001) definiram vetores que precedem o valor do cliente e a importância relativa destes vetores pode variar de setor para setor. Gupta e Zeithaml (2006) destacaram métricas do que os clientes pensam como termômetro de atitude de compra e como estas respectivas métricas se relacionam e quais os impactos para a empresa.

Além das variáveis externas, as variáveis internas também impactam a avaliação econômica de clientes. Dentre as variáveis internas que podem influenciar o valor do cliente, destacou-se o objetivo estratégico que motiva a avaliação econômica do cliente que pode influenciar os valores (SVEIBY, 2007), a interação entre ativos para a geração de valor com destaque para marca e clientes (BICK, 2009; LEONE et al., 2006). E, por último, as ações de marketing realizadas pela empresa para influenciar positivamente o ciclo de vida do cliente para a empresa e/ou acionista (BOLTON; LEMON; VERHOEF, 2002).

Berger et al. (2006) propuseram que o comportamento do cliente é o vetor-chave para a operação da empresa e que a agregação do comportamento individual de cada cliente dirige o comportamento global de mercado. Na estrutura disponível destacaram o ambiente competitivo ou condições raras de monopólio que influenciam nas políticas de preços, margens, custos de aquisição e nas taxas de retenção dos clientes. Também relacionaram a governança e a presença de níveis na estrutura de canal e suas implicações na divisão de lucros. Apontaram o objetivo de capitalização das companhias abertas e a expectativa dos analistas de mercado sobre os níveis de investimento, riscos, credores, taxa de crescimento, múltiplos de lucro, entre outros (BERGER et al., 2006).

Entre as variáveis externas, o momento do ciclo de vida do cliente ou da família do cliente pode indicar propensão a comprar mais produtos ou categorias complementares (VERHOEF; DONKERS, 2001; LIBAI; NARAYANDAS; HUMBY, 2002) ou ainda para o ciclo do produto, por exemplo, produtos duráveis como o carro, ciclos de compra de um ano para calcular projeções das taxas são mais indicados (BLATTBERG; DEIGHTON, 1996). Outros fatores externos, de mercado, podem impactar os fluxos de caixa (risco e retorno) das empresas. Exemplos desses fatores são: risco de mercado, tamanho da empresa, cliente, fatores do momento da empresa, 
competitividade do setor, participação de mercado, entre outros que fogem do escopo desta pesquisa e podem ser melhor referenciados nos trabalhos de Bowman e Narayandas (2004) e Srinivasan e Hanssens (2009).

Rust, Zeithaml e Lemon (2001) apontaram evidências de que fatores de mercado como entrada de novos concorrentes e ações da concorrência afetam o valor do cliente. Conforme, Rust, Zeithaml e Lemon (2001), os vetores que influenciam o valor do cliente variam de setor para setor. Os autores citam exemplos de clientes que dão mais importância para a marca na escolha de companhias aéreas do que para escolher uma locadora de veículos, identificando que alguns segmentos são voltados para transações (curto prazo) enquanto outros são voltados para relacionamento (longo prazo). Além disto, o ambiente competitivo influencia tanto fatores da empresa quanto os custos de prospecção e retenção, além de aumentar a chance de migração de clientes (RUST; ZEITHAML; LEMON, 2001).

No modelo de Rust, Zeithaml e Lemon (2001, p. 64), o valor do cliente baseia-se em três vetores acionáveis do ponto de vista do cliente que são: valor do valor, valor da marca e o valor de retenção, ilustrado na figura 10 . 0 valor do valor caracteriza-se pela avaliação objetiva, de utilidade de uma marca, da relação entre aquilo que é percebido como valor e o quanto se paga daquilo que se percebeu como valor entregue, sendo qualidade, preço e conveniência seus determinantes (RUST; ZEITHAML; LEMON, 2001).

O valor da marca é definido como a avaliação subjetiva e intangível da marca pelo cliente, sendo influenciada pelas ações de marketing da empresa e pelas experiências e associações do cliente em relação à marca. O valor de retenção é a percepção do cliente sobre a força da relação entre ele e a empresa, sendo influenciada por programas de lealdade, de reconhecimento, de afinidade, entre outros (RUST; ZEITHAML; LEMON, 2001).

O valor da marca ganha importância em ambientes onde o envolvimento no processo de decisão é simples, quando o produto é altamente visível para outras pessoas, quando a experiência com o produto pode ser passada de geração a geração e quando é difícil avaliar a qualidade de um serviço antes do consumo, como hotéis, por exemplo. Já o valor de retenção é mais importante quando os benefícios que os clientes associam aos programas são maiores que os benefícios reais, quando os produtos estão associados a algum 
grupo, comunidade ou movimento social, quando a relação de aprendizado entre empresa e cliente é benéfica para ambos e quando não é necessária a ação do cliente para cancelar os serviços como seguros e telefonia (RUST; ZEITHAML; LEMON, 2001).

Dentre as variáveis internas que influenciam o CLV e CE para a empresa foram ressaltadas o objetivo que motiva a avaliação, a interação entre ativos - clientes e marcas - e as ações empresariais sobre a gestão dos instrumentos de marketing.

Conforme evidenciado que os antecedentes empresariais também impactam o valor do cliente (GUPTA; ZEITHAML, 2006), Sveiby (2007) definiu quais objetivos motivam a avaliação de clientes. A interação entre ativos para a geração de valor foi destacada como a relação entre clientes e marcas, que são os ativos mais valiosos (BICK, 2009; LEONE et al., 2006). Os instrumentos de marketing, como ações de marketing e canais, possuem o objetivo de influenciar positivamente o ciclo de vida do cliente (BOLTON; LEMON; VERHOEF, 2002).

\section{DESCRIÇÃO DOS RESULTADOS E DISCUSSÃO}

Com base na revisão bibliográfica realizada na primeira etapa desta pesquisa, com aprofundamento nos casos empíricos, chegou-se a seguinte definição:

- Cliente é um ativo intangível. Cliente é um recurso escasso, desejado, assediado e caro de manter, sendo estes fatores mais intensos em mercados competitivos.

- Cliente é um ativo intangível quando estoca valor na medida em que consolida benefícios criados a partir das interações. São estes conhecimentos aliados a recursos e competências empresariais que influenciam positivamente o valor do cliente ao longo de seu ciclo de vida.

- Cliente como ativo intangível justifica-se, pois, a informação de mercado é um benefício latente, remoto, que precisa ser acessada 
mediante interações entre empresa e clientes, e essa informação é transformada em conhecimento, que, por sua vez, deve ser transformado em recurso, em capital intelectual da organização que transformada em valor monetário em algum ponto no futuro.

- Cliente é um ativo tangível na medida em que interage com outros ativos tangíveis (produtos e maquinários) e intangíveis (marcas e conhecimento) para a cocriação de valor.

- Cliente possui relação direta com a geração de fluxo de caixa enquanto outros intangíveis não a têm.

Foram levantadas 151 referências das quais 120 foram apresentadas na revisão bibliográfica da primeita eatapa desta pesquisa entre livros, artigos, teses e dissertações. Os 31 trabalhos restantes não foram incluídos por falta de acesso ao conteúdo global do artigo ou porque não se encaixavam ao o escopo desta pesquisa, abordando, por exemplo, avaliação de outros ativos de marketing como marca, satisfação, lealdade ou avaliação de diferentes ações de marketing, por exemplo, ações em canais e promoções, sem relacioná-los ao valor do cliente. Dos 120 trabalhos referenciados na revisão bibliográfica da primeira etapa, 33 artigos foram selecionados devido ao caráter aplicado e a relativa contribuição de cada caso para responder a pergunta e atender os objetivos específicos que originaram esta pesquisa.

Conforme observou Sveiby (2007), a definição do objetivo influencia no método de avaliação. Das 33 pesquisas, 15 destinaram-se à análise do padrão de lucratividade, 9 contemplaram a otimização da alocação de recursos, 4 relacionaram o valor do cliente ao valor de mercado da empresa, 3 abordaram o processo de aquisição e retenção, 1 abordou a imporância dos efeitos sociais entre clientes e 1 sobre a importância dos canais de comunicação e dos canais de compra.

Embora a ideia inicial fosse encontrar padrão a respeito das variáveis que compõem a avaliação de clientes para as empresas, na literatura internacional, o CLV e CE constituem um eixo de pesquisa que se divide em diferentes especialidades (BERGER; NASAR, 1998; SINGH; JAIN, 2002; BICK, 2006). O campo de investigação sobre avaliação de clientes pode ser categorizado por tipos de variáveis modeladas conforme o trabalho de Petersen 
et al. (2009), no qual esta pesquisa se inspirou para realizar o corte dos artigos.

Dos 10 anos analisados de 2000 a 2009, 2004 e 2007 foram os anos de maior representação desta amostra, enquanto no ano de 2002 nenhum estudo empírico foi encontrado. Anterior ao ano de 2000 foram inclídas as pesquisas de Blattberg e Deighton (1996) e Dwyer (1997) devido a importância desses destes autores para esta linha de pesquisa e para o enriquecimento da análise e discussões.

Os artigos empíricos provieram de 21 revistas diferentes. Da revista "Journal of Marketing" foram selecionados 4 casos, da revista "Expert System with Application" foram selecionados 3 casos e assim por diante. Notou-se que a concentração dos casos se deu em pesquisa no campo de marketing interativo e marketing de serviços, reforçando a descrição de Berger e Nasr (1998), Singh e Jain (2002), Gupta e Lehmann (2003), Nenonen e Storbacka (2008) de que o campo de pesquisa sobre o valor econômico do cliente teve origem no desenvolvimento do marketing de serviços para campanhas de marketing direto e tem se limitado ao domínio do marketing.

Dos 33 artigos selecionados, 20 acessam o valor do cliente por meio de estimação de taxas médias, entendido como modo agregado, conforme classificação de George e Kumar (2007). Libai, Narayandas e Humby (2002), no entanto, já haviam destacado a importância em se acessar informações detalhadas no nível do cliente para melhorar a eficiência da gestão, ou para melhorar a segmentação e seleção para investimentos das campanhas de marketing direto, como destacaram Rust et al. (2004) e George e Kumar (2007). Por outro lado, Kumar, Lemon e Parasuraman (2006) afirmaram que no modo agregado favorece a perspectiva de longo prazo que orienta a lucratividade da empresa.

Foram realizados (13 vetores de valor em cada um dos 33 casos) 429 julgamentos. Os vetores de valor estão no eixo x enquanto o eixo y representa o número de casos. Das possibilidades do aumento da receita, apontando a preponderância do aumento da receita pela retenção e prospecção de novos clientes e pela venda de produtos adicionais (up e cross selling). Já o aumento da receita por meio de fonte de informação e acompanhamento das tendências 
para inovação e renovação do negócio, referenciais positivos de clientes e aumento de preço para segmentos específicos, além da identificação de oportunidade para reduzir custos na retenção e prospecção, foram vetores negligenciados. A diminuição do risco do término da relação e da concentração e correlação dos negócios foram abordados por 19 e 13 casos, respectivamente.

Dos 33 casos selecionados, quase metade (15 casos) foi classificada para análise dos padrões de lucratividade. Todos os 15 casos acessaram o vetor de valor para aumento de receita por meio da retenção de clientes e diminuição do risco da informação fornecida aos gerentes. Dentre os 15 casos, apenas 6 identificaram a redução de custos, 2 na prospecção e 4 na retenção, corroborando a primeira geração de Jackman e Shanahan (2002), em que o foco se deu apenas em acessar a informação, porém não se desenvolveram oportunidades para rezudir custos. Benoit e Van den Poel (2009) afirmaram que raramente são confrontadas as características dos clientes lucrativos e dos não lucrativos. A análise do padrão de lucratividade de clientes dos 15 casos evidenciados teve por objetivo obter informação e conhecimento sobre os clientes mais lucrativos sem confrontá-los com características de clientes menos lucrativos ou ainda clientes que destroem valor.

Nas revisões de Berger e Nasr (1998) e Jain e Singh (2002) os modelos determinísticos são baseados na margem líquida de cliente, trazida a valor presente, onde receita e custo variam ao longo do tempo em que o cliente permanece com a empresa, e determinam o valor do cliente para a empresa. O modelo básico do CLV é relativamente simplista (BERGER; NASR, 1999; JAIN; SINGH, 2002) e falha em analisar o risco associado às dinâmicas do relacionamento do cliente no ambiente competitivo. Reinartz e Kumar (2000 e 2003) identificaram baixa correlação entre o tempo de permanência do cliente na a empresa e a lucratividade, indicando que a retenção nem sempre é lucrativa.

Enquanto os vetores que formam a lucratividade do cliente para Reinartz e Kumar, (2000 e 2003), Kumar, Shah e Venkatesan (2006), Kumar et al., (2008) e Kumar e Shah (2009) são formados por modelagem da frequência de compra, margem de contribuição e custos de marketing, para Rust, Lemon e Zeithaml (2001 e 2004) os vetores do valor do cliente são valor do valor, valor 
da marca e valor de retenção. Os vetores apontados pelos autores aproximam o valor dos clientes a atender os vetores de valor julgados pelos acionistas (SRIVASTAVA; SHERVANI; FAHEY, 1998; STAHL; MATZLER; HINTERHUBER, 2002; STORBACKA; NENONEN, 2009), Os vetores de Nenonen e Storbacka, (2009) são mais próximos da abordagem de Kumar e colegas, pois são mais objetivos em contemplar oportunidades de cross e up selling, número de contatos, custos de marketing, quantidade comprada aos fatores comportamentais dos clientes como o modelo de Rust, Lemon e Zeithaml (2001 e 2004).

Os vetores do valor do cliente podem ser comportamentais (RUST; LEMON; ZEITHAML, 2001 e 2004) ou atitudinais como abordam Kumar e colegas. Se a apuração de resultados por cliente assume novas perspectivas frente à avaliação financeira tradicional em que a análise da lucratividade do cliente é auferida com base no comportamento, a projeção do comportamento futuro exposto às mudanças do ambiente competitivo (BERGER et al., 2006; SRINIVASAN; HANSSENS; 2009) constituem um desafio para a construção dos modelos para o cálculo do CLV e CE, corroborando com Rust, Zeithaml e Lemon (2001), Bowman e Narayandas (2004), Malthouse e Blatteberg (2005), Berger et al. (2006), Fader, Hardie e Lee (2006), Srinivasan e Hanssens (2009).

Os resultados do instrumento de pesquisa estão disponíveis no quadro 1 abaixo. Os casos foram postados em ordem cronológica, trazendo primeiro os casos mais antigos e por último os casos mais recentes. 


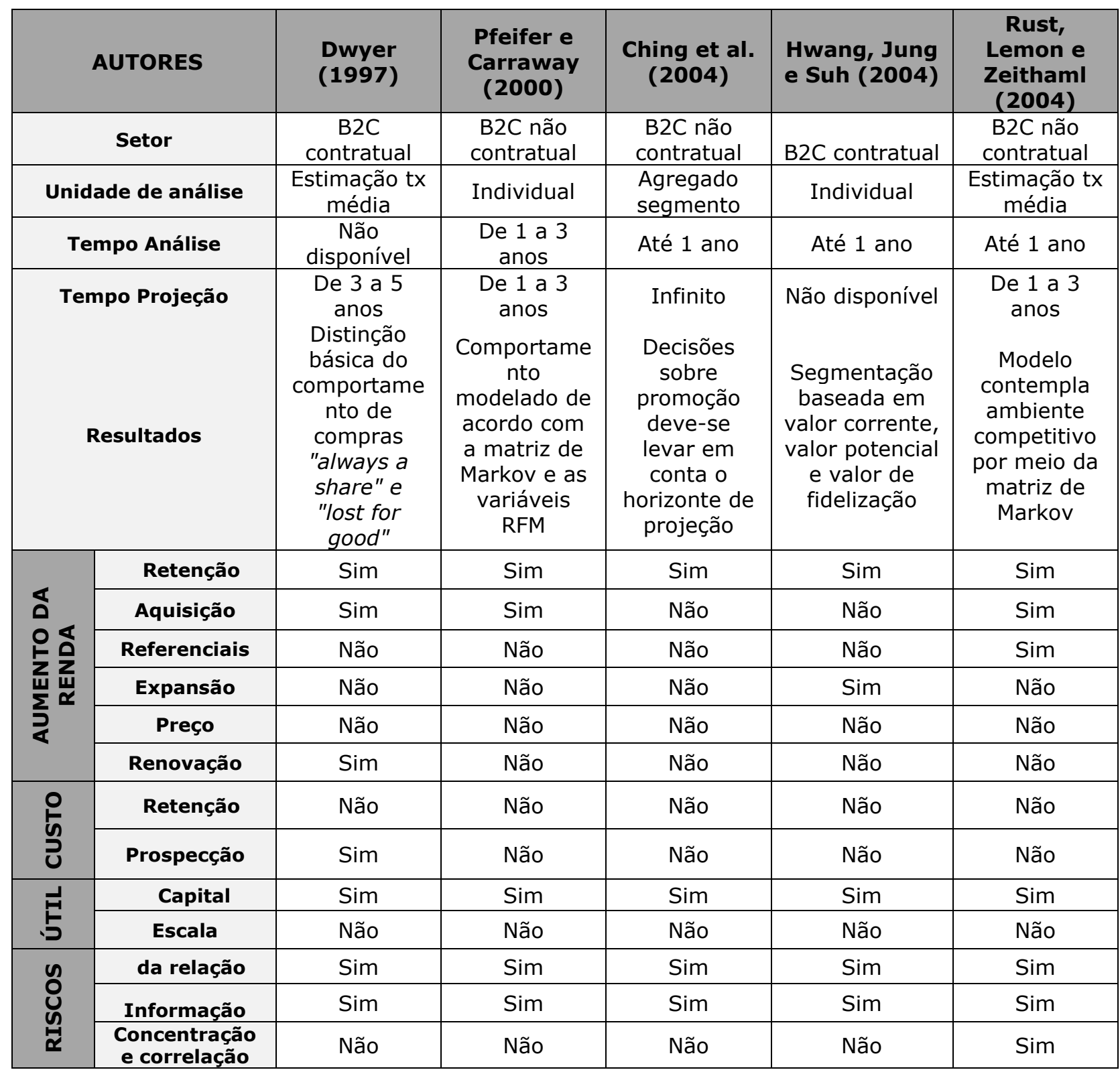

Quadro 1- Casos e a otimização de alocação de recursos (continua) 


\begin{tabular}{|c|c|c|c|c|c|}
\hline \multicolumn{2}{|c|}{ AUTORES } & $\begin{array}{c}\text { Donnevert e } \\
\text { Hammerschmidt } \\
\text { (2007) }\end{array}$ & $\begin{array}{c}\text { Tirenni, Kaiser e } \\
\text { Herrmann } \\
(2007)\end{array}$ & $\begin{array}{l}\text { Tirenni et al. } \\
\text { (2007) }\end{array}$ & $\begin{array}{c}\text { Malthouse e } \\
\text { Derenthal } \\
(2008)\end{array}$ \\
\hline & Setor & B2C não contratual & B2C não contratual & B2C não contratual & $\begin{array}{l}\text { B2C não } \\
\text { contratual }\end{array}$ \\
\hline \multicolumn{2}{|c|}{ Unidade de análise } & $\begin{array}{l}\text { Agregado } \\
\text { segmento }\end{array}$ & Agregado & $\begin{array}{l}\text { Estimação tx } \\
\text { média }\end{array}$ & Agregado \\
\hline \multicolumn{2}{|c|}{ Tempo Análise } & Não disponível & De 1 a 3 anos & De 1 a 3 anos & De 1 a 3 anos \\
\hline \multicolumn{2}{|c|}{ Tempo Projeção } & Não disponível & Até 1 ano & De 1 a 3 anos & Não aplicável \\
\hline \multicolumn{2}{|c|}{ Resultados } & $\begin{array}{c}\text { Segmentação por } \\
\text { meio de avaliação } \\
\text { de clientes } \\
\text { direciona os } \\
\text { investimentos }\end{array}$ & $\begin{array}{l}\text { Utilizou árvore de } \\
\text { decisão para } \\
\text { segmentar clientes }\end{array}$ & $\begin{array}{c}\text { Utilizou } \\
\text { programação } \\
\text { dinâmica para } \\
\text { seleção de clientes } \\
\text { para campanhas }\end{array}$ & $\begin{array}{l}\text { Melhora na } \\
\text { predição por } \\
\text { meio de } \\
\text { agregação de } \\
\text { dados }\end{array}$ \\
\hline \multicolumn{2}{|c|}{$\begin{array}{c}\text { Racionalização } \\
\text { Crítica }\end{array}$} & $\begin{array}{l}\text { Não testaram as } \\
\text { respostas dos } \\
\text { clientes, se houve } \\
\text { resposta superior } \\
\text { dos clientes } \\
\text { indicados }\end{array}$ & $\begin{array}{l}\text { Valor do cliente } \\
\text { atribuído apenas } \\
\text { pelas receitas, sem } \\
\text { confrontar custos }\end{array}$ & $\begin{array}{l}\text { Configuração dos } \\
\text { parâmetros com a } \\
\text { extração de } \\
\text { amostra }\end{array}$ & $\begin{array}{l}\text { Melhora na } \\
\text { predição por } \\
\text { aumento do } \\
\text { intervalo de } \\
\text { confiança }\end{array}$ \\
\hline \multirow{6}{*}{ 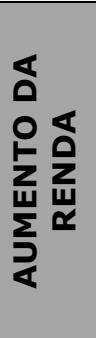 } & Retenção & Sim & $\operatorname{Sim}$ & Sim & $\operatorname{Sim}$ \\
\hline & Aquisição & Não & $\operatorname{Sim}$ & Não & $\operatorname{Sim}$ \\
\hline & Referenciais & Não & Não & Não & Não \\
\hline & Expansão & Não & Não & Sim & Não \\
\hline & Preço & Não & Não & Não & Sim \\
\hline & Renovação & Não & Não & Não & Não \\
\hline \multirow{2}{*}{ 음 } & Retenção & Sim & Não & Não & Não \\
\hline & Prospecção & Não & Não & Não & Não \\
\hline \multirow{2}{*}{ 혼 } & Capital & Sim & Sim & Sim & Sim \\
\hline & Escala & Não & Não & Não & Não \\
\hline \multirow{3}{*}{ 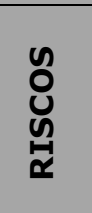 } & da relação & Não & Sim & Sim & Sim \\
\hline & Informação & Sim & Sim & Sim & Sim \\
\hline & $\begin{array}{c}\text { Concentraçã } \\
\text { o e } \\
\text { correlação }\end{array}$ & Não & Não & Sim & Não \\
\hline
\end{tabular}

Quadro 1 - Casos selecionados para a discussão sobre otimização da alocação de recursos (continuação)

Os casos selecionados para a discussão sobre aquisição e retenção foram 5. Verifica-se uma predominância no aumento da receita e redução do custo por meio de retenção, bem como a otimização da utilização dos recursos proporcionada pela tomada de decisão mais estruturada, diminuindo o risco da informação fornecida aos gerentes.

Os casos classificados como aquisição e retenção relacionados no quadro 5 podem ser entendidos também como otimização de aplicação de recursos, 
no entanto optou-se pela preferência em se destacar esses casos pela importância da contribuição de cada um (BARDIN, 2008; FLICK, 2009).

\begin{tabular}{|c|c|c|c|c|c|c|}
\hline \multicolumn{2}{|r|}{ AUTORES } & $\begin{array}{l}\text { Blattberg e } \\
\text { Deighton } \\
\text { (1996) }\end{array}$ & $\begin{array}{l}\text { Thomas } \\
(2001)\end{array}$ & $\begin{array}{c}\text { Hogan, } \\
\text { Lemon e } \\
\text { Libai (2003) }\end{array}$ & $\begin{array}{c}\text { Venkatesan } \\
\text { e Kumar } \\
(2004)\end{array}$ & $\begin{array}{c}\text { Reinartz, } \\
\text { Thomas e } \\
\text { Kumar (2005) }\end{array}$ \\
\hline & Setor & $\begin{array}{l}\text { B2C não } \\
\text { contratual }\end{array}$ & $\begin{array}{l}\text { B2C não } \\
\text { contratual }\end{array}$ & $\begin{array}{l}\text { B2C não } \\
\text { contratual }\end{array}$ & $\begin{array}{l}\text { B2C não } \\
\text { contratual }\end{array}$ & B2B indústria \\
\hline & Unidade & Agregado & Agregado & Agregado & Individual & Agregado \\
\hline \multicolumn{2}{|r|}{ Resultados } & $\begin{array}{l}\text { Balanceament } \\
\text { o entre } \\
\text { aquisição e } \\
\text { retenção }\end{array}$ & $\begin{array}{l}\text { Aquisição e } \\
\text { retenção não } \\
\text { são } \\
\text { independent } \\
\text { es } \\
\end{array}$ & $\begin{array}{l}\text { Custo de } \\
\text { perda de } \\
\text { clientes, } \\
\text { considerou } \\
\text { efeitos sociais }\end{array}$ & $\begin{array}{c}\text { Possível } \\
\text { melhorar o CLV } \\
\text { por canais de } \\
\text { comunicação }\end{array}$ & $\begin{array}{l}\text { Considerou } \\
\text { custos dos } \\
\text { canais de } \\
\text { comunicação }\end{array}$ \\
\hline \multicolumn{2}{|c|}{$\begin{array}{c}\text { Racionalização } \\
\text { Crítica }\end{array}$} & $\begin{array}{l}\text { Não aplicado, } \\
\text { aquisição e } \\
\text { retenção } \\
\text { independentes }\end{array}$ & $\begin{array}{l}\text { Aplicado em } \\
\text { amostra, } \\
\text { dados não } \\
\text { totalmente } \\
\text { disponível }\end{array}$ & $\begin{array}{c}\text { Extensão de } \\
\text { produtos } \\
\text { 3333adicionai } \\
\text { s não foi } \\
\text { analisada }\end{array}$ & $\begin{array}{l}\text { Rateio de } \\
\text { custos de } \\
\text { marketing }\end{array}$ & $\begin{array}{c}\text { Abordou } \\
\text { aquisição e } \\
\text { retenção e } \\
\text { lucratividade } \\
\text { independentes }\end{array}$ \\
\hline \multirow{6}{*}{$\begin{array}{l}\frac{\pi}{0} \\
0 \\
0 \\
\frac{5}{2} \\
\frac{2}{2} \\
\frac{\mathrm{w}}{\alpha} \\
\frac{\alpha}{\alpha}\end{array}$} & Retenção & Sim & Sim & Sim & Não & Sim \\
\hline & Aquisição & Sim & Sim & Sim & Não & Não \\
\hline & Referenciais & Não & Não & Não & Sim & Não \\
\hline & Expansão & Não & Não & Sim & Não & Sim \\
\hline & Preço & Não & Não & Não & Não & Não \\
\hline & Renovação & Não & Não & Não & Não & Sim \\
\hline \multirow{2}{*}{ 占 } & Retenção & Não & Sim & $\operatorname{Sim}$ & Não & Sim \\
\hline & Prospecção & Não & Sim & Sim & Não & Não \\
\hline \multirow{2}{*}{5} & Capital & $\operatorname{Sim}$ & Sim & $\operatorname{Sim}$ & Não & $\operatorname{Sim}$ \\
\hline & Escala & Não & Não & Sim & Não & Sim \\
\hline
\end{tabular}

Quadro 2 - Casos e aquisição, retenção variáveis comportamentais e referenciais

Embora o CLV e o CE sejam apresentados como um balizador de valor (KUMAR; LEMON; PARASURAMAN, 2006; GUPTA; ZEITHAML, 2006; BERGER et al.,2006) o CLV caracteriza o valor futuro que o cliente representa para a empresa, não abordando o valor entregue ou percebido pelo cliente. Nenonen e Storbacka (2009) afirmaram que não há geração de valor para a empresa se não houver criação de valor para o cliente. Donnevert e Hammerschmidt (2007), sob esta perspectiva, propuseram uma segmentação combinada entre o valor do cliente para a empresa e no valor percebido pelo cliente. No entanto, as respostas desta segmentação não foram testadas para a verificação de perforance superior frente à segmentação realizada no CLV. 
Dos 9 casos selecionados para a discussão, todos contemplaram a obtenção de receita por meio da campanha de retenção de clientes e a redução do risco da informação fornecida aos gerentes para melhorar a tomada de decisão quanto a aplicação de recursos em relação a clientes. Dos 9 casos, 8 abordaram o risco da descontinuidade da relação e 5 apontaram o aumento da receita por meio de campanhas de atração de novos clientes, avaliando o processo de aquisição.

Os vetores aumento da receita por referenciais de clientes, identificação de oportunidades de cross e up selling, identificação de aumento de preço para segmentos específicos bem como a redução de custo na prospeção e retenção e economia de escala foram negligenciados nesses 9 casos e refletem a característica geral da amostra dos 33 casos. Tal fato pode ser atribuído ao foco das ações em identificar clientes mais lucrativos para campanhas de retenção, conforme Berger, Nasr, (1998) e Jain e Singh (2002), assinalando que a linha de pesquisa encontra-se na sua infância, testandos maneiras inovadoras de avaliar e quantificar as relações com os clientes, uma vez que a retenção e fidelização nem sempre são lucrativos (REINARTZ; KUMAR, 2000, 2003) sendo que o sentido da relação destas variáveis não é bem estabelecido (GUPTA; ZEITHAML, 2006).

Para a otimização da alocação de recursos, o CLV é associado a diferentes fatores para a segmentação e seleção de clientes. Tirenni, Kaiser e Herrmann (2007) usaram o montante de receitas, sem a confrontação de custos, associadas às variáveis psicográficas aplicando a ferramenta de árvore de decisão para definir os segmentos. Verhoef e Donkers (2001), Donkers, Verhoef e Jong (2003) propuseram a segmentação baseada dois atributos, um no valor realizado e o outro no valor futuro dos clientes.

Os casos selecionados para discussão sobre otimização de alocação de recursos estão dispostos no quadro abaixo (quadros 3,4) em ordem cronológica, trazendo primeiro os casos mais antigos e por último os casos mais recentes. 


\begin{tabular}{|c|c|c|c|c|c|c|}
\hline & AUTORES & $\begin{array}{l}\text { Dwyer } \\
(1997)\end{array}$ & $\begin{array}{c}\text { Pfeifer e } \\
\text { Carraway } \\
\text { (2000) }\end{array}$ & $\begin{array}{l}\text { Ching et al. } \\
\text { (2004) }\end{array}$ & $\begin{array}{l}\text { Hwang, } \\
\text { Jung e } \\
\text { Suh } \\
(2004)\end{array}$ & $\begin{array}{c}\text { Rust, Lemon } \\
\text { e Zeithaml } \\
\text { (2004) }\end{array}$ \\
\hline & Setor & $\begin{array}{c}\mathrm{B} 2 \mathrm{C} \\
\text { contratual }\end{array}$ & $\begin{array}{l}\text { B2C não } \\
\text { contratual }\end{array}$ & $\begin{array}{l}\text { B2C não } \\
\text { contratual }\end{array}$ & $\begin{array}{c}\mathrm{B} 2 \mathrm{C} \\
\text { contratual }\end{array}$ & $\begin{array}{l}\text { B2C não } \\
\text { contratual }\end{array}$ \\
\hline \multicolumn{2}{|c|}{ Unidade de análise } & $\begin{array}{l}\text { Estimação } \\
\text { tx média }\end{array}$ & Individual & $\begin{array}{l}\text { Agregado } \\
\text { segmento }\end{array}$ & Individual & $\begin{array}{c}\text { Estimação tx } \\
\text { média }\end{array}$ \\
\hline \multicolumn{2}{|c|}{ Tempo Análise } & $\begin{array}{c}\text { Não } \\
\text { disponível }\end{array}$ & $\begin{array}{l}\text { De } 1 \text { a } 3 \\
\text { anos }\end{array}$ & Até 1 ano & Até 1 ano & Até 1 ano \\
\hline \multicolumn{2}{|c|}{ Tempo Projeção } & $\begin{array}{l}\text { De } 3 \text { a } 5 \\
\text { anos }\end{array}$ & $\begin{array}{c}\text { De } 1 \text { a } 3 \\
\text { anos }\end{array}$ & Infinito & $\begin{array}{c}\text { Não } \\
\text { disponível }\end{array}$ & De 1 a 3 anos \\
\hline \multicolumn{2}{|r|}{ Resultados } & $\begin{array}{l}\text { Distinção } \\
\text { básica do } \\
\text { comportam } \\
\text { ento de } \\
\text { compras } \\
\text { "always a } \\
\text { share" e } \\
\text { "lost for } \\
\text { good" }\end{array}$ & $\begin{array}{c}\text { Comportame } \\
\text { nto } \\
\text { modelado de } \\
\text { acordo com } \\
\text { a matriz de } \\
\text { Markov e as } \\
\text { variáveis } \\
\text { RFM }\end{array}$ & $\begin{array}{c}\text { Decisões } \\
\text { sobre } \\
\text { promoção } \\
\text { deve-se levar } \\
\text { em conta o } \\
\text { horizonte de } \\
\text { projeção }\end{array}$ & $\begin{array}{c}\text { Segmentaç } \\
\text { ão baseada } \\
\text { em valor } \\
\text { corrente, } \\
\text { valor } \\
\text { potencial e } \\
\text { valor de } \\
\text { fidelização }\end{array}$ & $\begin{array}{c}\text { Modelo } \\
\text { contempla } \\
\text { ambiente } \\
\text { competitivo } \\
\text { por meio da } \\
\text { matriz de } \\
\text { Markov }\end{array}$ \\
\hline \multirow{6}{*}{ 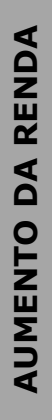 } & Retenção & Sim & Sim & $\operatorname{Sim}$ & Sim & Sim \\
\hline & Aquisição & Sim & Sim & Não & Não & Sim \\
\hline & Referenciais & Não & Não & Não & Não & Sim \\
\hline & Expansão & Não & Não & Não & Sim & Não \\
\hline & Preço & Não & Não & Não & Não & Não \\
\hline & Renovação & Sim & Não & Não & Não & Não \\
\hline \multirow{2}{*}{$\begin{array}{l}0 \\
\frac{6}{3} \\
0\end{array}$} & Retenção & Não & Não & Não & Não & Não \\
\hline & Prospecção & Sim & Não & Não & Não & Não \\
\hline \multirow{2}{*}{ 본 } & Capital & Sim & Sim & Sim & Sim & Sim \\
\hline & Escala & Não & Não & Não & Não & Não \\
\hline \multirow{3}{*}{ 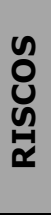 } & da relação & Sim & Sim & $\operatorname{Sim}$ & Sim & Sim \\
\hline & Informação & Sim & Sim & Sim & Sim & Sim \\
\hline & $\begin{array}{c}\text { Concentração e } \\
\text { correlação }\end{array}$ & Não & Não & Não & Não & Sim \\
\hline
\end{tabular}

Quadro 3- Casos e a otimização de alocação de recursos (continua) 


\begin{tabular}{|c|c|c|c|c|c|}
\hline \multicolumn{2}{|c|}{ AUTORES } & $\begin{array}{c}\text { Donnevert e } \\
\text { Hammerschmi } \\
\text { dt (2007) }\end{array}$ & $\begin{array}{l}\text { Tirenni, Kaiser e } \\
\text { Herrmann (2007) }\end{array}$ & $\begin{array}{l}\text { Tirenni et al. } \\
\text { (2007) }\end{array}$ & $\begin{array}{c}\text { Malthouse e } \\
\text { Derenthal (2008) }\end{array}$ \\
\hline & Setor & $\begin{array}{c}\text { B2C não } \\
\text { contratual }\end{array}$ & B2C não contratual & B2C não contratual & B2C não contratual \\
\hline & $\begin{array}{c}\text { Unidade de } \\
\text { análise }\end{array}$ & $\begin{array}{l}\text { Agregado } \\
\text { segmento }\end{array}$ & Agregado & $\begin{array}{l}\text { Estimação tx } \\
\text { média }\end{array}$ & Agregado \\
\hline \multicolumn{2}{|r|}{ Tempo Análise } & Não disponível & De 1 a 3 anos & De 1 a 3 anos & De 1 a 3 anos \\
\hline \multicolumn{2}{|c|}{ Tempo Projeção } & Não disponível & Até 1 ano & De 1 a 3 anos & Não aplicável \\
\hline \multicolumn{2}{|r|}{ Resultados } & $\begin{array}{c}\text { Segmentação } \\
\text { por meio de } \\
\text { avaliação de } \\
\text { clientes } \\
\text { direciona os } \\
\text { investimentos }\end{array}$ & $\begin{array}{l}\text { Utilizou árvore de } \\
\text { decisão para } \\
\text { segmentar clientes }\end{array}$ & $\begin{array}{c}\text { Utilizou } \\
\text { programação } \\
\text { dinâmica para } \\
\text { seleção de clientes } \\
\text { para campanhas }\end{array}$ & $\begin{array}{c}\text { Melhora na } \\
\text { predição por meio } \\
\text { de agregação de } \\
\text { dados }\end{array}$ \\
\hline \multicolumn{2}{|r|}{$\begin{array}{l}\text { Racionalização } \\
\text { Crítica }\end{array}$} & $\begin{array}{l}\text { Não testaram } \\
\text { as respostas } \\
\text { dos clientes, se } \\
\text { houve resposta } \\
\text { superior dos } \\
\text { clientes } \\
\text { indicados }\end{array}$ & $\begin{array}{l}\text { Valor do cliente } \\
\text { atribuído apenas } \\
\text { pelas receitas, sem } \\
\text { confrontar custos }\end{array}$ & $\begin{array}{l}\text { Configuração dos } \\
\text { parâmetros com a } \\
\text { extração de } \\
\text { amostra }\end{array}$ & $\begin{array}{c}\text { Melhora na } \\
\text { predição por } \\
\text { aumento do } \\
\text { intervalo de } \\
\text { confiança }\end{array}$ \\
\hline \multirow{6}{*}{ 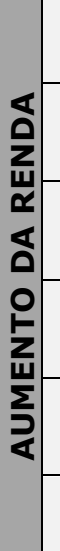 } & Retenção & Sim & Sim & Sim & Sim \\
\hline & Aquisição & Não & Sim & Não & Sim \\
\hline & Referenciais & Não & Não & Não & Não \\
\hline & Expansão & Não & Não & Sim & Não \\
\hline & Preço & Não & Não & Não & Sim \\
\hline & Renovação & Não & Não & Não & Não \\
\hline \multirow{2}{*}{ 인 } & Retenção & Sim & Não & Não & Não \\
\hline & Prospecção & Não & Não & Não & Não \\
\hline \multirow{2}{*}{5} & Capital & Sim & Sim & Sim & Sim \\
\hline & Escala & Não & Não & Não & Não \\
\hline \multirow{3}{*}{ ڤ. } & da relação & Não & Sim & Sim & Sim \\
\hline & Informação & Sim & Sim & Sim & Sim \\
\hline & $\begin{array}{l}\text { Concentração } \\
\text { e correlação }\end{array}$ & Não & Não & Sim & Não \\
\hline
\end{tabular}

Quadro 4 - Casos selecionados para a discussão sobre otimização da alocação de recursos (continuação)

Se os ativos intangíveis estão fora dos balancos contábeis (COLAUTO, et al., 2008; RUST et al., 2004; STAHL; MATZLER; HINTERHUBER; 2002, SRIVASTAVA; SHERVANI; FAHEY, 1998), Wiesel, Skiera e Villanueva (2007) propuseram acompanhar trimestralmente o estado e o fluxo da taxa de 
retenção de clientes, o custo com aquisição de clientes, o número total de clientes, o número de clientes adquiridos, o número de clientes perdidos e, por último, o fluxo de caixa de clientes conforme estrutura e critérios dos relatórios financeiros. A estrutura foi desenvolvida na Netfix.com, que possui capital aberto na NASDAQ e tem como principal negócio alugar filmes por internet.

Dos 33 casos, 4 foram escolhidos para discussão dos resultados em relação ao valor do cliente e valor de mercado da empresa. Em relação ao tamanho da busca e o número de casos aplicados, esta linha de pesquisa embora jovem, surge como uma promessa de contemplar sinergias que a contabilidade tradicional não integra nos demonstrativos obrigatórios e se apresenta como alternativa para àquelas empresas que buscam capturar valores intangíveis, determinantes de valor da economia atual (LEV, 2001; KAYO, 2002; GUPTA; LEHMANN, 2003; GUPTA; LEHMANN; STUART, 2004; GUPTA; LEHMANN, 2006; FAMA; PEREZ, 2005; KAYO et al., 2006 ; COLAUTO et al., 2008).

A forte ligação entre o valor do cliente e o valor de mercado da empresa demonstrada por estas pesquisas permite assinalar que a concepção de clientes como ativos é de suma importância e caracteriza um terreno fértil tanto para a área acadêmica quanto para a prática.

\section{Considerações finais}

Embora esta pesquisa não seja conclusiva, permitiu-se assinalar os principais tópicos da revisão realizada integrando o conhecimento acerca da avaliação econômica de clientes e da gestão de clientes por valor. O campo de investigação sob avaliação de clientes é relativamente novo e vasto e têm aumentado o interesse tanto prático quanto acadêmico. A configuração da economia atual fundamentada que a geração de valores anormais é promovida pelo conhecimento, pelo intangível, a gestão de clientes por ativos assume preponderância para empresas que buscam otimizar a utilização de seus ativos. Clientes apresentam a característica intrínseca dos ativos intangíveis, no entanto, mesmo identificados como ativos intangíveis, não são reconhecidos pelas normas nacionais e internacionais para registro nos balanços contábeis. Assim, as empresas assumem o leque da contabilidade 
gerencial para avaliar e quantificar as relações dos clientes com a empresa, assinalando iniciativas em evidenciar estes ativos em relatórios gerenciais e relatórios da administração.

Conforme revisão da literatura e proposta por esta pesquisa, o Valor Vitalício (CLV) e o Valor da Carteira (CE) surgem como métricas balizadoras em resposta à demanda para tornar o marketing mais produtivo e responsável e comprometido com as outras funções da empresa, posicionando o marketing no hall das decisões estratégicas. A avaliação de clientes por meio do CLV e do CE promovem o conhecimento acerca da estrutura de geração de valor do negócio em relação a clientes e otimizam a alocação de recursos para a tomada de decisão, proporciando instrumentos para a gestão de clientes para influenciar positivamente o ciclo de vida do cliente, e assim, gerar valor aos acionistas.

A metodologia de avaliação também pode ser influenciada pela (in) disponibilidade de dados nas empresas, pode ser calculada com a informações disponíveis nos relatórios e balanços das companhias abertas e pelo objetivo que motivou o cálculo. Os primeiros modelos desta linha de pesquisa apresentaram a estrutura de avaliação financeira tradicional utilizando o método do fluxo de caixa descontado pelo custo médio de capital. No entanto, esta estrutura é limitada, pois não contempla o ambiente competitivo e os efeitos sociais característicos de mercados onde as relações sociais são intensas.

Dado a tendência do marketing de serviços e do marketing interativo indivíduo a indivíduo, o CLV proporciona gestão individualizada dos clientes, melhorando a alocação de recursos para os mais diferentes desafios enfrentados pelos gerentes, seja em campanhas de prospeção ou de retenção. $\mathrm{O} \mathrm{CE}$, por sua vez, oferece a direção dos resultados futuro do negócio. A concepção da avaliação econômica de clientes assinala a mudança do foco da gestão de ativos antes voltada para a mensuração de ativos internos as empresas, agora voltadas a avaliação de ativos de mercado (SRIVASTAVA; SHERVANI; FAHEY, 1998).

Dos casos empíricos apontados nesta pesquisa, permite-se assinalar a tendência da iniciativa das empresas em analisar o padrão da lucratividade da base atual dos clientes para se investir em retenção, corroborando afirmações 
de Jain e Singh (2002) e Berger e Nasr (1998), embora possa ser uma decisão equivocada, pois fidelidade pode não estar relacionada a lucratividade (KUMAR; SHAH; VENKATESAN, 2006). Ainda assim, a motivação para se avaliar clientes busca otimizar a alocação de recursos com o objetivo de tornar o marketing mais comprometido e produtivo para credibildade do marketing nas decisões estratégias, uma vez que o CLV e o CE são instrumentos que quantificam a relação dos clientes.

Embora os modelos que avaliam o ciclo de vida do cliente devessem projetar o valor do cliente por toda a vida, os modelos adotam um horizonte de projeção de 3 anos, pois consideram uma relativa estabilidade para ações de marketing. Permite constatar que poucos modelos se atentatarm pela realidade dinâmica da tomada de decisão dos gerentes, com exceção de Tirenni et al. (2007) que desenvolveu uma estrutura flexível para o cálculo do CLV a qualquer tempo. As pesquisas mais recentes relacionam o valor do cliente a capitalização de mercado.

Desta maneira, o cálculo do CLV e do CE tem sido redefinido nos últimos dez anos em relação ao modelo original de Blattberg e Deigthon (1996), espandindo sua aplicação e descobrindo relações valoráveis a cada contexto específico. As métricas que determinam o valor do cliente são aquisição e retenção, venda cruzada e aumento de consumo (cross e up selling), comportamento de compra por vários canais, referenciais de clientes e retorno de produtos são os vetores identificados nesta pesquisa coincidem com as mesmas métricas indicadas por Petersen et al. (2009) para maximizar o lucro e o valor aos shareholders.

A discussão sobre clientes, embora seja de grande amplitude na graduação pouco se fala sobre seus impactos na gestão do negócio sob a abordagem de geração de valor para a empresa e/ou acionistas. Pode-se assinalar que o tema reforça a integração entre finanças e marketing como marca o pioneirismo de Srivastava, Shervani e Fahey (1998). O levantamento dos desdobramentos socioeconômicos bem como a forma de acumulação de capital reforça que a gestão de clientes por valor deve ser tratada não apenas na disciplina de marketing, mas também em outras esferas como finanças, contabilidade, estatística e modelagem além das disciplinas sobre sistemas de informação. Esta afirmação reforça a proposta da dissertação de Grinberg 
(2001) em que o valor de clientes foi entendido como parte integrante da disciplia proposta por ele de métricas de marketing.

Pesquisa em área social é um grande desafio devido as diversificações de base de dados disponíveis para levantamento de artigos, já sinalizados na limitação desta pesquisa. Espera-se que a partir da sintetização obtida com o esforço deste trabalho de referenciação e catalogação de pesquisas empíricas como conceituais para o desenvolvimento do tema, seja de grande valia para a elucidação das futuras pesquisas neste campo de investigação. Conforme apontado por Bick (2009), Leone (2006), Kumar, Lemon e Parasuram (2006) e Rust et. al., (2004) são raras as pesquisas que abordam a relação entre valor do cliente e o valor do acionista, acionando a necessidade de pesquisas adicionais em que este trabalho se amparou.

Os estudos destacados indicam predominância do aumento da renda por meio de retenção, enquanto outros vetores de valor foram negligenciados como risco e estrutura de capital, corroborando Nenonen e Storbacka 2008. Também a relação do valor do cliente e a capacidade de gerar valor no curto e longo prazo com a integração do intervalo de resposta do comportamento do cliente são essenciais para a gestão dos instrumentos de marketing.

Houve clara predominância de serviços e varejo, sendo exemplos em mercados B2B escassos, constituindo um campo fértil para futuras pesquisas. Pesquisas adicionais são necessárias em aquisição e retenção, a elucidação das interações sociais entre os clientes e os impactos para a empresa, pois os clientes não são entidades ou pessoas isoladas. Também são necessárias investigações adicionais em métricas que guiem para o futuro e não apenas projeções de padrões passados. Análises complementares para consolidar ou desmistificar a influência da gestão dos instrumentos de marketing no valor do cliente e a relação do valor dos clientes com a capitalização de mercado.

Finalizando, a interação de ativos para a cocriação de valor ainda é um campo pouco explorado. 


\section{REFERÊNCIAS}

BARDIN, L. Análise de Conteúdo. 5. ed. Lisboa: Edições 70, 2008.

BARRETO, I. F. Avaliação de resultados de ações de marketing de relacionamento. 2007. 207 f. Dissertação (Mestrado em Administração) Faculdade de Economia e Administração de São Paulo, São Paulo, 2007.

BATISLAM, E. P.; DENIZEL, M.; FILIZTEKIN, A. Empirical validation and comparison of models for customer base analysis. International Journal of Research in Marketing, Netherlands, v. 24, n. 3, p. 201-209, 2007.

BAUER, H. H.; HAMMERSCHMIDT, M. Customer-based corporate valuation: Integrating the concepts of customer equity and shareholder value. Management Decision, West Yorkshire, v. 43, n. 3, p. 331-348, 2005.

BAYÓN, T.; GUTSCHE, J.; BAUER, H. Customer Equity Marketing: Touching the Intangible. European Management Journal, Paris, v. 20, n. 3, p. 213-222, 2002.

BERGER, P. D. et al. From Customer Lifetime Value to Shareholder Value: Theory, Empirical Evidence, and Issues for Future Research. Journal of Service Research, Boston, v. 9, n. 2, p. 156-167, 2006.

BERGER, P. D.; NASR, N. I. Customer lifetime value: marketing models and applications. Journal of Interactive Marketing, Florida, v. 12, p. 17-30, 1998.

BICK, G. N. C. Increasing shareholder value through building Customer and Brand Equity. Journal of Marketing Management, v. 25, p. 117-141, 2009.

BLATTBERG, R. C.; DEIGHTON, J. Manage Marketing by the Customer Equity Test. Harvard Business Review, Boston, n.74, p. 136-44, ago. 1996.

BLATTBERG, R. C.; GETZ, G.; THOMAS, J. S. Customer equity: building and managing relationship as valuable assets. Boston: Harvard Business Shoool Press, 2001.

BLATtBerG, R. C.; MALThOUSE, E. C.; NESLIN, S. A. Customer Lifetime Value: Empirical Generalizations and Some Conceptual Questions. Journal of Interactive Marketing, v. 23, n. 2, p. 157-168, 2009.

BOLTON, R. N.; LEMON, K. N.; VERHOEF, P. C. The Theoretical Underpinnings of Customer Asset Management. SSRN, 2002

BORLE, S, SINGH, S. S.; JAIN, D. C. Customer lifetime value measurement. Management Science, Philadelphia, v. 54, p. 100-112, 2007.

BOWMAN, D.; NARAYANDAS, D. Linking Customer Management Effort to Customer Profitability in Business Markets. American Marketing Association, v. 41, n. 4, p. 433-447, 2004. 
BRASIL. Lei $\mathrm{n}^{\circ} 11.638$, de 28 de dezembro de 2007. Altera e revoga dispositivos da Lei no 6.404, de 15 de dezembro de 1976, e da Lei no 6.385, de 7 de dezembro de 1976, e estende às sociedades de grande porte disposições relativas à elaboração e divulgação de demonstrações financeiras. Diário Oficial da União, Brasília, DF, 28 dez. 2007. Edição Extra.

CHING, W-K. et al. Customer Lifetime Value: stochastic opitization approach. Journal of the Operational Research Society, v. 55, p. 860-868, 2004.

COLAUTO, R. D. et al. Evidenciação de Ativos Intangíveis não adquiridos nos relatórios da administração das companhias listadas nos níveis de governança corporativa da Bovespa. In: ENANPAD, 32, 2008, Rio de Janeiro. Anais eletrônicos... Rio de Janeiro: ANPAD, 2008. CD-ROM.

COMISSÃO DE PRONUNCIAMENTOS CONTÁBEIS [CPC 01]. Pronunciamento Técnico CPC 01 - Redução no Valor Recuperável de Ativos. Brasília: CPC, 2008. Disponível em: < http://www.cpc.org.br/pdf/cpc01-audienciapublica.pdf>. Acesso em: fev. 2016.

COMISSÃO DE PRONUNCIAMENTOS CONTÁBEIS [CPC]. Sumário do Pronunciamento Conceitual Básico Estrutura Conceitual para a Elaboração e Apresentação das Demonstrações Contábeis. Brasília: CPC, 2008. Disponível em: < http://www.cpc.org.br/pdf/sumario_estruturaconceitual.pdf>. Acesso em: fev. 2016.

COMISSÃO DE VALORES MOBILIÁRIOS [CVM]. Comitê de Pronunciamentos Contábeis: Sumário do pronunciamento técnico CPC 04: Ativo Intangível. Brasília: CPC, 2008. Disponível em: $<$ www.cvm.gov.br/port/infos/deli553\%20-

\%20sum\%C3\%A1rio\%20(CPC04).pdf>. Acesso em: fev. 2016.

COOLING, D.; BAXTER, N. Valuing Customers. BT Technology Journal, v. 23, n. 3, jul. 2005.

COOPER, D. R.; SCHILNDLER, P. S. Métodos de Pesquisa de Administração. Tradução de Luciana de Oliveira Rocha. Porto Alegre: Bookman, 2003.

COSTA, P. D. D. et al. Goodwill: uma análise dos conceitos utilizados em trabalhos científicos. Controladoria e Contabilidade USP, Ribeirão Preto, v. 9, n. 16, jul. 2009.

DAMODARAN, A. Avaliação de Investimentos - Ferramentas e Técnicas para a Determinação do Valor de Qualquer Ativo. Rio de Janeiro: Qualitymark Editora Ltda., 1997

DONKERS, B.; VERHOEF, P.; JONG, M Modeling CLV: A test of competing models in the insurance industry. Quantitative Marketing Economics, v. 5, n. 2, p. 163-190, 2007.

DONKERS, B.; VERHOEF, P.; JONG, M. Predicting Customer Lifetime Value in Multi-Service Industries. Rotterdan: Erasmus Research Institute of Management, Rotterdan School of Management, 2003. 
DWYER, F. R. Customer lifetime valuation to support marketing decision making. Journal of Direct Marketing, v. 11, n. 4, p. 6-13, 1997.

FADER, P. S.; HARDIE, B.; JERATH, K. Estimating CLV using aggregated data: the Tuscan lifestyles case revisited. Journal of Interactive Marketing, $v$. 21, n. 3, 2007.

FADER, P.; HARDIE, B.; LEE, K. L. "Counting your customers" the easy way: An alternative to the Pareto/NBD Model. Marketing Science, v. 24, n. 2, p. 275284, 2005a.

FADER, P.; HARDIE, B.; LEE, K. L. CLV: More than meets the eye. Technical report. American Marketing Association, 2006. Disponível em: http://ssrn.com/abstract=913338. Acesso em: 11 ago 2010.

FADER, P.; HARDIE, B.; LEE, K. L. RFM and CLV: Using Iso-Value Curves for Customer Base Analysis. Journal of Marketing Research, v. 42, p. 415-430, 2005b.

FAMA, E.F. Efficient Capital Markets: A Review of Theory and Empirical Work. Journal of Finance, volume 25: Dezembro 1969.

FINANCIAL ACCOUNTING STANDARDS BOARD [FASB]. Statement of Financial Accounting Standards No. 141: business Combination. 2001. Disponível em: <http://www.fasb.org/pdf/aop_FAS141.pdf.> Acesso em: fev 2016.

FLICK, U. Introdução à pesquisa qualitativa. Tradução de Joice Elias Costa, 3. ed., Porto Alegre: Artmed, 2009.

GARLAND, R. Share of wallet's role in customer profitability. Journal of Financial Services Marketing, v. 8, n. 3, p. 259-168, 2004.

GITMAN, L. J. Princípios de Administração Financeira. São Paulo: Pearson Prentice Hall, 2009.

GLADY, N.; BAESENS, B.; CROUX, C. A modified Pareto/NBD approach for predicting customer lifetime value. Expert System with Applications, v. 36, n. 2, p. 2062-2071, 2007.

GOODCHILD, J.; CALLOW, C. Brands: visions \& values. Londres: John Wiley, 2001.

GOULART, A. M. C. O conceito de Ativos na Contabilidade: Um fundamento a ser explorado. Revista de Contabilidade \& Finanças USP, n. 28, p. 56-65, abr. 2002.

GRINBERG, C. S. Marketing Metrics. Um estudo exploratório sobre a construção do conhecimento de um novo tema em marketing. 2001. Dissertação (Mestrado em Administração) - Universidade Federal do Rio Grande do Sul, Rio Grande do Sul, 2001.

GUPTA, S. Customer-Based Valuation. Journal of Interactive Marketing, v. 23, n. 2, p. 169-178, 2009. 
GUPTA, S. et al. Modeling customer lifetime value. Journal of Service Research, v. 9, n. 2, p. 139-155, 2006.

GUPTA, S.; LEHMANN, D. R. Customers as assets. Journal of Interactive Marketing, v. 17, n. 1, p. 9-24, 2003.

GUPTA, S.; LEHMANN, D. R. Gerenciando Clientes como Investimentos: o valor estratégico dos clientes a longo prazo. Porto Alegre: Bookman, 2006.

GUPTA, S.; LEHMANN, D. R.; STUART, J. A. Valuing Customers. Journal of Marketing Research, v. 41, p. 1-18, fev. 2004.

GUPTA, S.; ZEITHAML, V. Customer Metrics and Their Impact and Financial Performance. Marketing Science, n. 25, p. 687-717, jun. 2006.

HOGAN, J. E. et al. Linking Customer Assets to Financial Performance. Journal of Service Research, v. 5, n. 1, p. 26-38, ago. 2002.

HOGAN, J. E.; LEMON, K. N.; LIBAI, B. What Is the True Value of a Lost Customer? Journal of Service Research, v. 5, n. 3, p. 196-208, 2003.

HWANG, H.; JUNG, T.; SUH, E. An LTV model and customer segmentation based on customer value: a case study on the wireless telecommunication industry. Expert System with Applications, v. 26, n. 2, p. 181-188, 2004.

INTERNATIONAL ACCOUNTING STANDARDS BOARD [IASB]. Framework for the Preparation and Presentation of Financial Statements. London: IASB, 2004. Disponível em: <http://www.iasplus.com/agenda/framework.htm>. Acesso em: fev. 2010.

INTERNATIONAL ACCOUNTING STANDARDS BOARD [IASB]. Management Comentary.Disponível em: <http://www.iasb.org/Home.htm>. Acesso em: fev. 2010.

IUDICIBUS, S.; MARTINS, E. Uma investigação e uma proposição sobre o conceito e o uso do valor justo. Contabilidade e finanças da USP, São Paulo, $\mathrm{n}$. $18,2007$.

IUDICIBUS, S.; MARTINS, E; CARVALHO, L. N. Contabilidade: aspectos relevantes da epopéia de sua evolução. Revista de Contabilidade e Finanças da USP, São Paulo, n. 38, 2005.

JACKMAN, S. M.; SHANAHAN, Y. Customer Profitability Analysis: Frustration Leads to Evolution. Journal on Applied Business Research, New Zealand, v. 1, n. 1, 2002.

JAIN, D.; SINGH, S. Customer Lifetime Value Research in Marketing: A review and Future Directions. Journal of Interactive Marketing, v. 16, n. 2, p. 3446, 2002.

KAYO, E. K. A estrutura de capital e o risco das empresas tangível e intangível-intensivas: uma contribuição ao estudo da valoração das empresas. 2002. Tese (Doutorado em Administração) - Faculdade de 
Economia, Administração e Contabilidade, Universidade de São Paulo, São Paulo, 2002.

KAYO, E. K. et al. Ativos intangíveis, ciclo de vida e criação de valor. RAC, v. 10, p. 73-90, 2006.

KOTLER, P. Administração de Marketing. 10. ed., New Jersey: Pearson Prentice Hall, 2000.

KOTLER, P.; KELLER, K. L. Administração de Marketing. 12. ed., São Paulo: Pearson Prentice Hall, 2006.

KUMAR, V. et al. The Power of CLV: Managing Customer Lifetime Value at IBM. Marketing Science, v. 27, n. 4, p. 585-599, jul. 2008.

KUMAR, V., VENKATESAN, R.; REINARTZ, W. Knowing What to Sell, When to Whom. Harvard Business Review, p. 131-137, mar. 2006.

KUMAR, V.; GEORGE, M. Measuring and maximizing customer equity: a critical analysis. Journal of the Academy of Marketing Science, v. 35, n. 2, p. 157-171, 2007.

KUMAR, V.; LEMON, K. N.; PARASURAMAN, A. Managing Customers for Value: An Overview and Research Agenda. Journal of Service Research, n. 9, p. 8794, nov. 2006.

KUMAR, V.; PETERSEN, J. A. Using a Customer-Level Marketing Strategy to Enhance Firm Performance: A Review of Theoretical and Empirical Evidence. Journal of Academy of Marketing Science, v. 33, n. 4, p. 504-519, 2005.

KUMAR, V.; RAMANI, G.; BOHLING, T. Customer lifetime value approaches and Best practice applications. Journal of Interactive Marketing, v. 18, n. 3, p. 60-72, 2004.

KUMAR, V.; SHAH, D. Expanding the role of marketing from Customer Equity Capitalization. Journal of Marketing, v. 73, p. 119-136, 2009.

KUMAR, V.; SHAH, D.; VENKATESAN, R. Managing retailer profitability - one customer at a time! Journal of Retailing, v. 82, n. 4, p. 277-294, 2006.

LEONE, R. P. et al. Linking Brand Equity to Customer Equity. Journal of Service Research, v. 9, n. 2, p. 125-138, nov. 2006.

LEV, B. Intangibles: Management, Measurement and Reporting. The International Journal of Accounting, v. 36, n. 4, p. 501-503, 2001.

LIBAI, B.; NARAYANDAS, D.; HUMBY, C. Toward as Individual Customer Profitability Model: A Segment-Based Approach. Journal of Service Research, v. 5, n. 69, 2002.

LUKAS, B. A.; WHITWELL, G. J.; DOYLE, P. How can a shareholder value approach improve marketing's strategic influence? Journal of Business Research, $v$. 58, n. 4, p. 414-422, 2003. 
MALTHOUSE, E. C.; BLATTBERG, R. C. Can we predict customer lifetime value? Journal of Interactive Marketing, v. 19, n. 1, p. 2-16, 2005.

MALTHOUSE, E. C.; DERENTHAL, K. M. Improving Predictive Scoring Models Trough Model Aggregation. Journal of Interactive Marketing, v. 22, n. 3, p. $18,2008$.

MARKETING SCIENCE INSTITUTE. Disponível em: < http://www.msi.org/research>. Acesso em: 28 nov. 2015.

MAYRING, P.; FLICK, U.; KARDOFF, E.; STEINKE, I. Qualitative Content Analysis A Companion to Qualitative Research. London, p. 266-269, 2004.

NENONEN, S.; STORBACKA, K. Customer relationships and the heterogeneity of firm performance. The Journal of Business and Industrial Marketing, v. 24, p. 360-372, 2009.

NENONEN, S.; STORBACKA, K. Customer Roles in Shareholder Value Creation - An Empirical Investigation of Customer Asset Management Strategies. Working Paper, 2008.

PEREZ, M. M.; FAMÁ, R. Ativos intangíveis e o desempenho empresarial. Revista Contabilidade \& Finanças, São Paulo, n. 40, p. 7-24, jan./abr. 2006.

PETERSEN, J. A. et al. Choosing the Right Metrics to Maximize Profitability and Shareholder Value. Journal of Retailing, v. 85, n. 1, p. 95-111, 2009.

PFEIFER, P. E.; CARRAWAY, R. L. Modeling customer relationships as Markov chains. Direct Marketing Educational Foundation, v. 14, n. 2, p. 43-55, 2000.

PFEIFER, P. E.; HASKINS, M. E.; CONROY, R. M. Customer lifetime value, customer profitability, and the treatment of acquisition spending. Journal of Managerial Issues, v. 26, 2004.

REINARTZ, W. J.; KUMAR, V. The impact of Customer Relationship on Profitable Lifetime Duration. Journal of Marketing, v. 67, p. 67-79, 2003.

REINARTZ, W. J.; KUMAR, V. On the Profitability of Long-Life Customers in a Noncontractual Setting: an empirical investigation and implications for marketing. Journal of Marketing, n. 64, p. 17-35, out. 2000.

REINARTZ, W. J.; THOMAS, J. S.; KUMAR, V. Balancing Acquisition and Retention Resources to Maximize Customer Profitability. American marketing Association, v. 69, n. 1, p. 63-79, 2005.

RICHARDSON, R. J. Pesquisa Social: métodos e técnicas. 3. ed., São Paulo: Atlas, 1999.

RUST, R. T. et al. Measuring marketing productivity: Current knowledge and future directions. American Marketing Association, v. 68, p. 76-89, 2004. 
RUST, R. T; LEMON, K. N.; ZEITHAML, V. A. Return on marketing: using customer equity to focus marketing strategy. Journal of Marketing, v. 68, n. 1, p. 109$127,2004$.

RUST, R. T; ZEITHAML, V. A.; LEMON, K. N. O Valor do Cliente: o modelo que está reformulando a estratégia corporativa. Porto Alegre: Bookman, 2001.

SILVEIRA, C. S. O encontro do valor do cliente com a bolsa de valores. 2007. 142 f. Dissertação (Mestrado em Administração) - Universidade Federal do Rio Grande do Sul, Porto Alegre, 2007.

SRINIVASAN, S.; HANSSENS, D. M. Marketing and Firm Value: Metrics, Methods, Finds, and Future Directions. American Marketing Association, v. 46, n. 3, jun. 2009.

SRIVASTAVA, R. K.; FAHEY, L.; CHRISTENSEN, H. K. The resource-based view and marketing: the role of market-based assets in gaining competitive advantage. Journal of Management, v. 27, n. 6, p. 777-802, nov. 2001.

SRIVASTAVA, R. K.; SHERVANI, T. A.; FAHEY, L. Market-Based Assets and Shareholder Value: A Framework for Analysis. Journal of marketing, v. 62, p. 2-18, jan. 1998.

STAHL, H. K.; MATZLER, K.; HINTERHUBER, H. H. Linking customer lifetime value with shareholder value. Industrial Marketing Management, v. 32, n. 4, p. 267-279, 2002.

SVEIBY, Karl-Erik. Methods for Measuring Intangible Assets. 2007. Disponível em: <http://www.sveiby.com/articles/IntangibleMethods.htm>. Acesso em: 14/05/2016.

THOMAS, J. S. A Methodology for Linking Customer Acquisition to Customer Retention. Journal of Marketing Research, n. 38, p. 262-268, 2001.

TIRENNI, G.; KAISER, C.; HERRMANN, A. Applying decision trees for value-based customer management: Predicting airline customers' future values. Journal Database Marketing Strategy Management, v. 14, n. 2, p. 130-142, 2007.

TIRENNI,G. et al. Customer equity and lifetime management (CELM) finnair case study. Marketing Science, v. 26, n. 4, p. 553-565, 2007.

VENKATESAN, R.; KUMAR, V. A customer lifetime value framework for customer selection and resource allocation strategy. Journal of Marketing, v. 68, n. 4, p. 106-125, 2004.

VERHOEF, P. C.; DONKERS, B. Predicting Customer Potencial Value: an application in the insurance industry. Rotterdan: Erasmus Research Institute of Management, Rotterdan School of Management, 2001.

WIERENGA, B. Handbook of Marketing Decision Models. Springer, 2008. Disponível em: < http://books.google.com.br>. Acesso em: mar. 2010. 
WIESEL, T.; SKIERA, B.; VILLANUEVA, J. Customer equity: An integral part of financial reporting. Journal of Marketing, v. 72, n. 2, p. 1-14, 2007.

XU, M.; WALTON, J. Gaining customer knowledge through analytical CMR. Industrial management \& Data System, v. 105, n. 7, p. 955-971, 2005.

ZIKMUND, W. G. Business Research Methods. 7. ed., Mason: Thomson SouthWestern, 2003. 